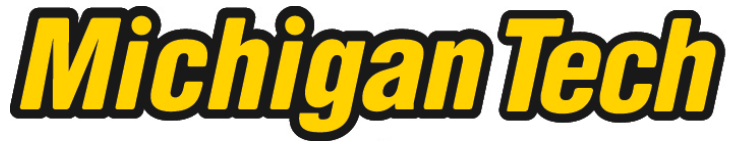 \\ Michigan Technological University Create the Future Digital Commons @ Michigan Tech
}

Dissertations, Master's Theses and Master's Reports - Open

Dissertations, Master's Theses and Master's

Reports

2014

ROLE OF MICRORNA LET-7 IN PANCREATIC BETA CELLS

Shungang Zhang

Michigan Technological University

Follow this and additional works at: https://digitalcommons.mtu.edu/etds

Part of the Molecular Biology Commons

Copyright 2014 Shungang Zhang

\section{Recommended Citation}

Zhang, Shungang, "ROLE OF MICRORNA LET-7 IN PANCREATIC BETA CELLS", Master's Thesis, Michigan Technological University, 2014.

https://doi.org/10.37099/mtu.dc.etds/797

Follow this and additional works at: https://digitalcommons.mtu.edu/etds

d. Part of the Molecular Biology Commons 


\title{
ROLE OF MICRORNA LET-7 IN PANCREATIC BETA CELLS
}

By

Shungang Zhang

\author{
A THESIS \\ Submitted in partial fulfillment of the requirements for the degree of \\ MASTER OF SCIENCE \\ In Biological Sciences \\ MICHIGAN TECHNOLOGICAL UNIVERSITY \\ 2014 \\ (C) 2014 Shungang Zhang
}


This thesis has been approved in partial fulfillment of the requirements for the Degree of MASTER OF SCIENCE in Biological Sciences.

\title{
Department of Biological Sciences
}

\author{
Thesis Advisor: $\quad$ Dr.Xiaoqing Tang \\ Committee Member: Dr.Tarun Dam \\ Committee Member: Dr.Guiliang Tang \\ Department Chair: Dr. Chandrashekhar P. Joshi
}




\section{Table of contents}

Acknowledgements ...................................................................................................iv

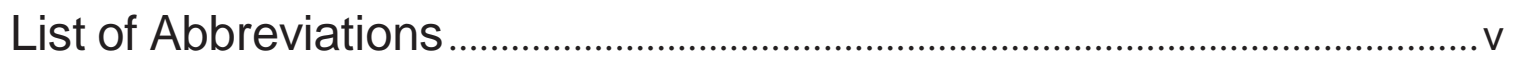

Abstract ................................................................................................................... vi

1. Introduction .............................................................................................................

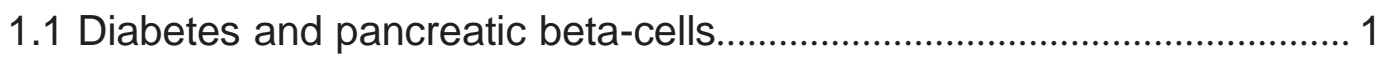

1.2 Role of microRNA in beta cells.............................................................. 4

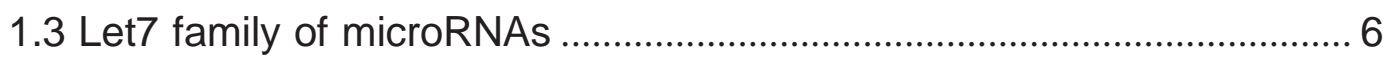

1.4 Methods to silence/block miRNA family function...................................... 7

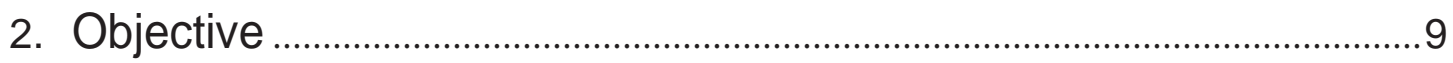

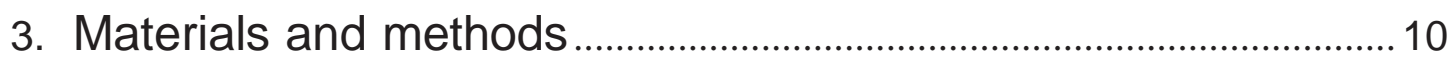

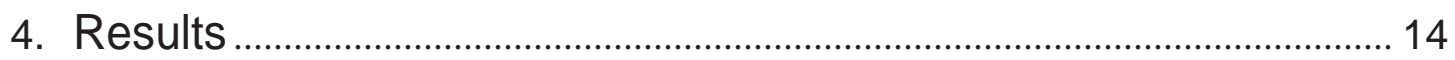

4.1 STTM-let7 reduces expression of let-7 in 1-cells............................... 14

4.2 Let-7 suppresses cell death by targeting caspase-3 ……....................... 15

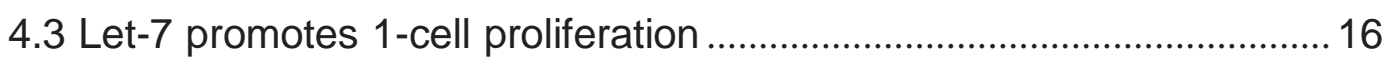

4.4 Let-7 positively regulates glucose-stimulated insulin secretion....... 17

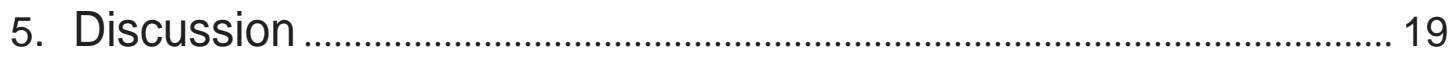

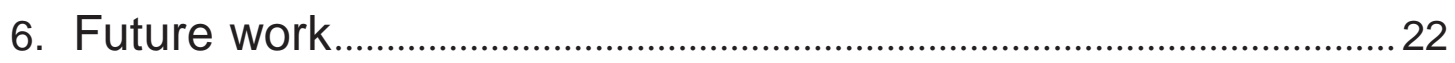

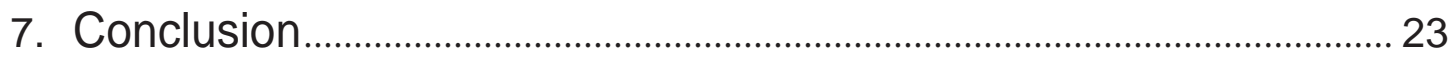

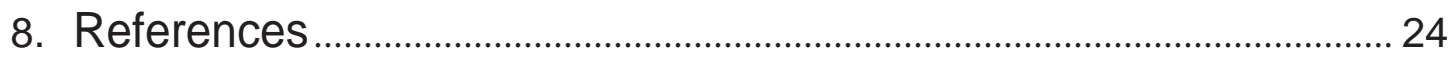




\section{Acknowledgements}

Thank you very much to my advisor Dr. Xiaoqing Tang. I am very lucky and pleased for having the opportunity to work with your guidance and to know and learn from you. I can't make it without your help to my life and study. Thank you to my committee members, Dr. Guiliang Tang and Dr. Tarun Dam. I am grateful to have your suggestions to my project. It is my pleasure to discuss with Dr. Guiliang Tang and get so many insightful advices. Thank you very much to Dr. Tarun Dam, one of the best teachers I came across in Michigan Tech. I hope one day I can be as intelligent and humorous as you are in the class. Thank you so much to my lab mates, Ramkumar Mohan and Yiping Mao for your patience teaching me laboratory techniques and your assistance in my work. Thank you to Mengmeng Qiao, Haiping Liu, Yiyou Gu and other students of Dr. Guiliang Tang. Thank you for allowing me to use the equipments in your lab and bringing a lot of pleasure in my daily life. Thank you for my parents who support me and encourage me all the time on the other side of the ocean. 


\section{List of abbreviations}

AGO2: Argonaute

EIF4EBP2: Eukaryotic translation initiation factor 4E binding protein 2

IGF1R: Insulin-like growth factor 1 receptor

INSR/IR: Insulin receptor

IRS-1/2: Insulin receptor substrate

ITT/GTT: Insulin tolerance tests/Glucose tolerance tests

GLUT: Glucose transporter

GSIS: Glucose stimulated insulin secretion

HMGA2: High mobility group AT-hook 2

MAP kinase: Mitogen-activated protein kinase

MODY genes: Maturity onset diabetes of youth genes

mTOR: mammalian target of rapamycin

MTPN: mytrophin

PDX-1: Pancreatic and duodenal homeobox 1

PI3 kinase: Phosphoinositide 3 kinase

PKB/Akt: protein kinase B

RISC: RNA-induced silencing complex

STTM: Short tandem target mimic

T1D: Type 1 diabetes

T2D: Type 2 diabetes

TNF-a: Tumor necrosis factor alpha

\section{Abstract}


MicroRNAs (miRNAs) are small non-coding RNAs that inhibit gene expression at transcriptional or post-transcriptional level. Let-7 family is among the first identified human miRNAs and regulates multiple cellular processes including glucose metabolism in multiple organs. It has been reported that overexpression of let-7 resulted in insulin resistance and impaired glucose tolerance through repressing insulin signaling pathway in both muscle and liver. However, the role and mechanism underlying let-7 function in pancreatic beta-cells have yet to be elucidated.

Let-7 family contains nine members, which poses a significant challenge in complete deletion of this miRNA family. To study the function of let-7 and to overcome the functional redundancies of various let- 7 members in pancreatic beta-cells, the highly expressed let-7a and let-7b were blocked simultaneously using short tandem target mimic (STTM) approach developed in our laboratory. Introducing STTM-let7 into beta-cells markedly increased the expression of Caspase 3, a direct target of let-7, confirming a sufficient functional knockdown of let-7a/b by STTM-let7. STTM-let7 enhanced apoptotic cell death induced by cytokine, indicating that let-7a/b is able to protect from apoptosis through attenuating Caspase 3 expression in pancreatic beta-cells. In contrast to the previous observation that let-7 silencing increases insulin signaling in muscle and liver, inhibition of let-7 with STTM-let7 significantly repressed glucose-stimulated insulin signaling in pancreatic beta-cells, leading to impaired insulin secretion and reduced beta-cell proliferation. Taken together, an appropriate level of let-7 is essential in maintaining beta-cell function and viability. Dysregulation of let-7 may contribute to the pathogenesis of type2 diabetes. 


\section{Introduction}

\subsection{Diabetes and pancreatic beta-cells}

Diabetes is a disorder of metabolism in which a person has high blood glucose level (hyperglycemia). If left untreated, hyperglycemia can cause serious complications, such as heart diseases and kidney failure(1). Diabetes is due to either insufficient amount of insulin or dysfunction of insulin effects on the body. There are three types of diabetes: type 1 diabetes, type 2 diabetes and gestational diabetes. Type 1 diabetes (T1D) is characterized by loss of insulinproducing pancreatic 1-cell caused by autoimmune attack on the 1-cells. Type 1 diabetes is usually diagnosed in children and young adults and previously called juvenile diabetes or "insulin-dependent diabetes"(2). Type 2 Diabetes (T2D) results from the combination of resistance to insulin action in muscle and adipocytes and insufficient insulin production 1-cells. Approximately $90 \%$ of diabetic patients are type 2 diabetes(3). Gestational diabetes is a type of diabetes that only occurs during pregnancy in females who previously did not have diabetes.

Type 2 Diabetes is one of the most prevalent diseases around the world. There were approximately 285 million people diagnosed with T2D in 2010(4).

Development of type 2 diabetes involves multiple metabolic defects, mainly due to insulin resistance and 1-cell dysfunction. Most people with insulin resistance fail to respond to normal circulating insulin, causing reduced glucose uptake in muscle and fat tissues, increased glucose production and release in liver, which all in turn result in elevated blood glucose levels(5).If insulin resistance exists, much higher insulin requires to be secreted to blood from pancreatic 1-cells, a condition called hyperinsulinemia(6). Hyperglycemia combined with hyperinsulinemia generate various toxicities, such as free fatty acids, reactive oxygen species and inflammatory cytokines, which result in 1-cell dysfunction including reduced insulin secretion and insulin biosynthesis, increased 1-cell death and eventually loss of 1-cell mass(7-9).

Pancreatic 1-cells are the only source for producing insulin and insulin is the key hormone responsible for maintaining glucose homeostasis. In 1-cell, insulin 
biosynthesis and release are tightly regulated by insulin signaling pathway that maintain the 1-cell fate and activate specific transcription factors in response to the change of plasma glucose(10). The insulin signaling pathway involvesinsulin activated insulin receptor (IR), insulin receptor substrate (IRS1/2), phosphorylation, and activation of phosphatidylinositol 3-kinase (PI3-K), Akt (also known as protein kinase B), and mammalian target of rapamycin (mTOR)(Figure 1.1)(10).Studies in diabetic animal models and humans have consistently demonstrated that dysregulation of insulin signaling is associated with impaired insulin secretion and insulin biosynthesis. Overexpression of insulin receptor in 1cells was found to promote insulin transcription and regulate the steady-state insulin content (11). Leibiger and his colleagues reported type A insulin receptor controlled insulin gene transcription whereas stimulation of type $B$ insulin receptor promoted 1-cell glucokinase gene expression (12). Insulin receptor substrate 2 (IRS-2) branch of the insulin/insulin-like growth factor signaling is capable of mediating pancreatic 1-cell proliferation and function. Exendin-4 promoted IRS-2 expression and Akt phosphorylation were able to delay progression of diabetes and to stimulate insulin secretion (13). IRS-2 was also shown to be regulated by negative feedback effects of mammalian target of rapamycin (mTOR). Chronic activation of mTOR resulted in degradation of IRS-2 followed by deactivation of Akt/PKB and elevation of 1-cell apoptosis.(14) This work provided another mechanism indicating why 1 -cell is damaged by chronic hyperglycemia in the development of type 2 diabetes. 


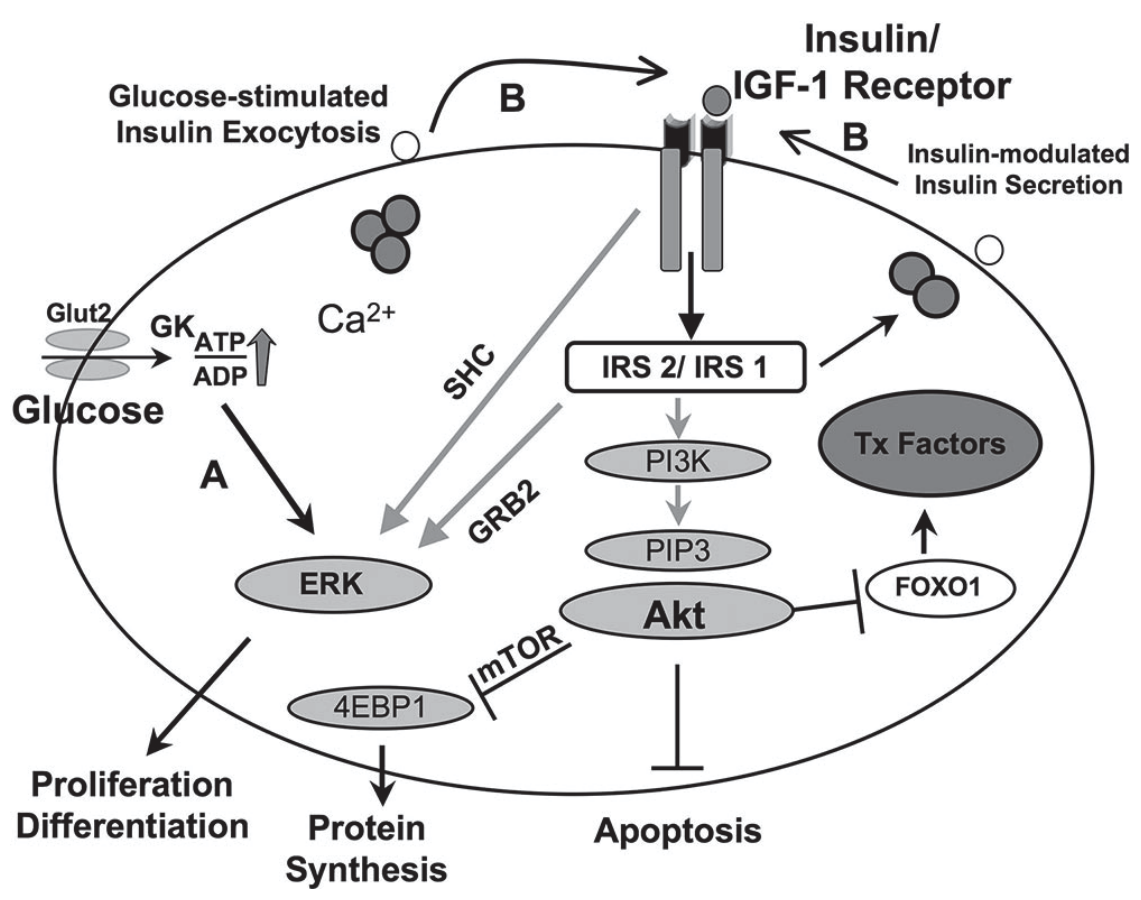

Figure 1.1 Glucose and insulin stimulated insulin signaling pathways in pancreatic 1-cells. Insulin molecules interact with Insulin receptor (IR) and activate both the mitogenic (via MAP kinase) and metabolic branches involving phosphoinositide 3 (PI3)-kinase, protein kinase B (PKB, also called Akt), mammalian target of rapamycin (mTOR). Adapted from (10).

The development of type 2 diabetes is associated with a loss of 1-cell mass. The 1 -cell mass is maintained by the dynamic balance of proliferation and cell death. Under normal conditions, the proliferation and apoptosis rate are very low(15). However, in the late phase of diabetes, 1-cell mass is significantly decreasing due to an enhanced 1-cell apoptosis. Evidences have demonstrated the proinflammatory cytokines stimulate 1-cell apoptosis by activating Bcl-2 regulated intrinsic apoptotic pathway(16)(Figure 1.2). The proapoptotic members, Bax and Bak, directly promote mitochondrial swelling and release of cytochrome C. Cytochrome $\mathrm{C}$ release leads to the formation of an apoptosome, which in turn activates caspase-3 and ultimately induces cell apoptosis $(17,18)$. Antiapoptotic $\mathrm{Bcl}-2$ family sequesters Bax and Bak in the cytosol, thus inhibiting apoptosis. Understanding how cytokine triggers 1-cell apoptosis is likely to shed new light 
on mechanisms of 1-cell loss in diabetes and may therefore find the way to improve therapeutic intervention.

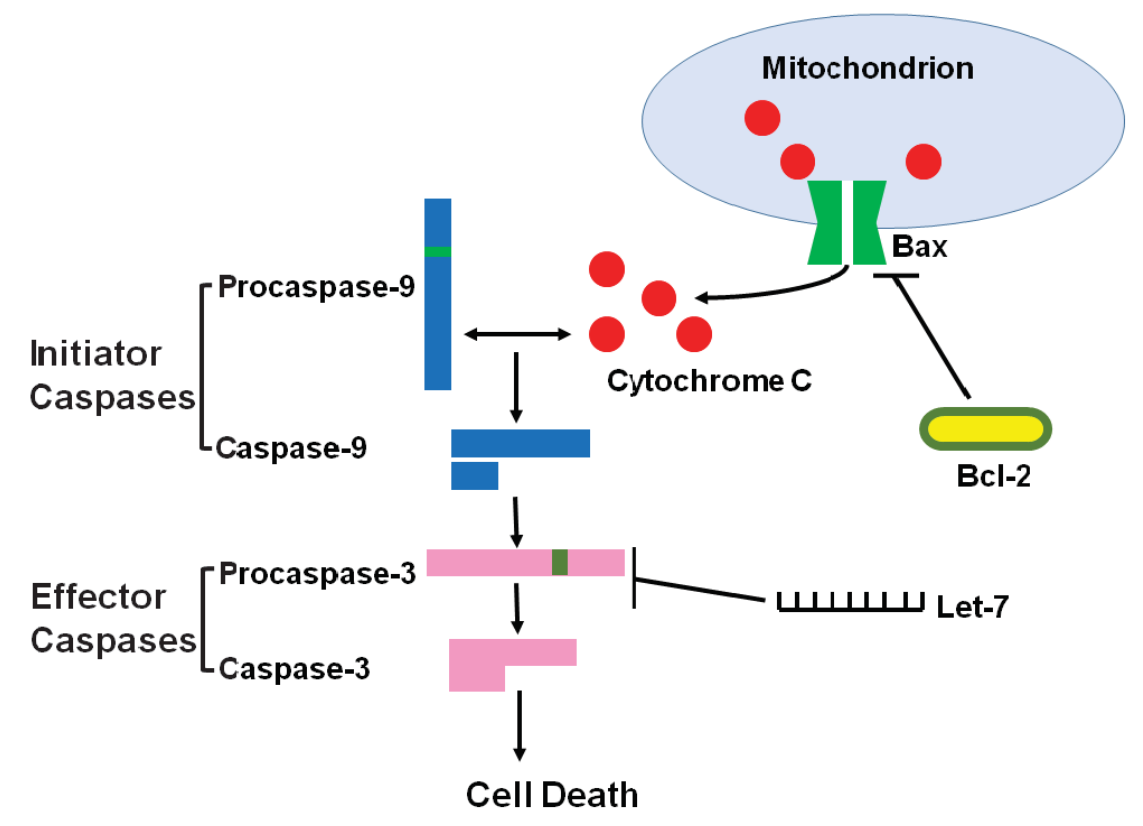

Figure 1.2 Diagram of cell death signaling. Cell death can be initiated through intrinsic pathway (Mitochondria) or extrinsic pathway (ligand-receptor binding).Both of them require the activation of initiator caspases (CASP8, CASP9) and effector caspases (CASP3). Let-7 was revealed to suppress the expression of Caspase-3 (19). Bax and Bcl-2 are antagonistic regulators mediate the release of Cytochrome $\mathrm{C}$ from mitochondria.

\subsection{Role of microRNA in beta cells}

MicroRNA (miRNA) is a small (-22 nucleotides) non-coding RNA located in the introns or non-coding region of genome. MiRNAs can be found in plants, animals and some virus, in which they regulate gene expression on transcriptional or post-transcriptional level. Containing the complementary sequences to the messenger RNA (mRNA), miRNAs interact with their target mRNA through base pairing, resulting in inhibition or degradation of the mRNA(20). In human body, miRNAs mainly repress translation by binding imperfectly with 3 '-untranslated region of their targets. Generally, one single miRNA regulates expression of multiple genes and one single mRNA is controlled by a combination of multiple 
miRNAs $(20,21)$.In animal cells, the biogenesis of miRNAs starts from transcribing miRNA genes to primary transcripts (pri-miRNAs) by RNA polymerase II (Pol II). The poly-A tail of pri-miRNA is cropped by the Drosh complex, generating the precursor miRNA (pre-miRNA) which has a hairpin structure with a -2-nucleotide 3 ' overhang. Pre-miRNA is recognized by exportin- 5 and transported into cytoplasm in which the pre-miRNA is cleaved by Dicer to produce miRNA duplex. Dicer and Argonaute (AGO2)(22) mediate the processing of pre-miRNA and assemble the RNA-induced silencing complex (RISC). One strand of the miRNA is degraded whereas the other is incorporated into AGO protein as the mature miRNA. AGO2 is responsible for possessing the inhibition of target $m R N A(23,24)$ (Figure 1.3).

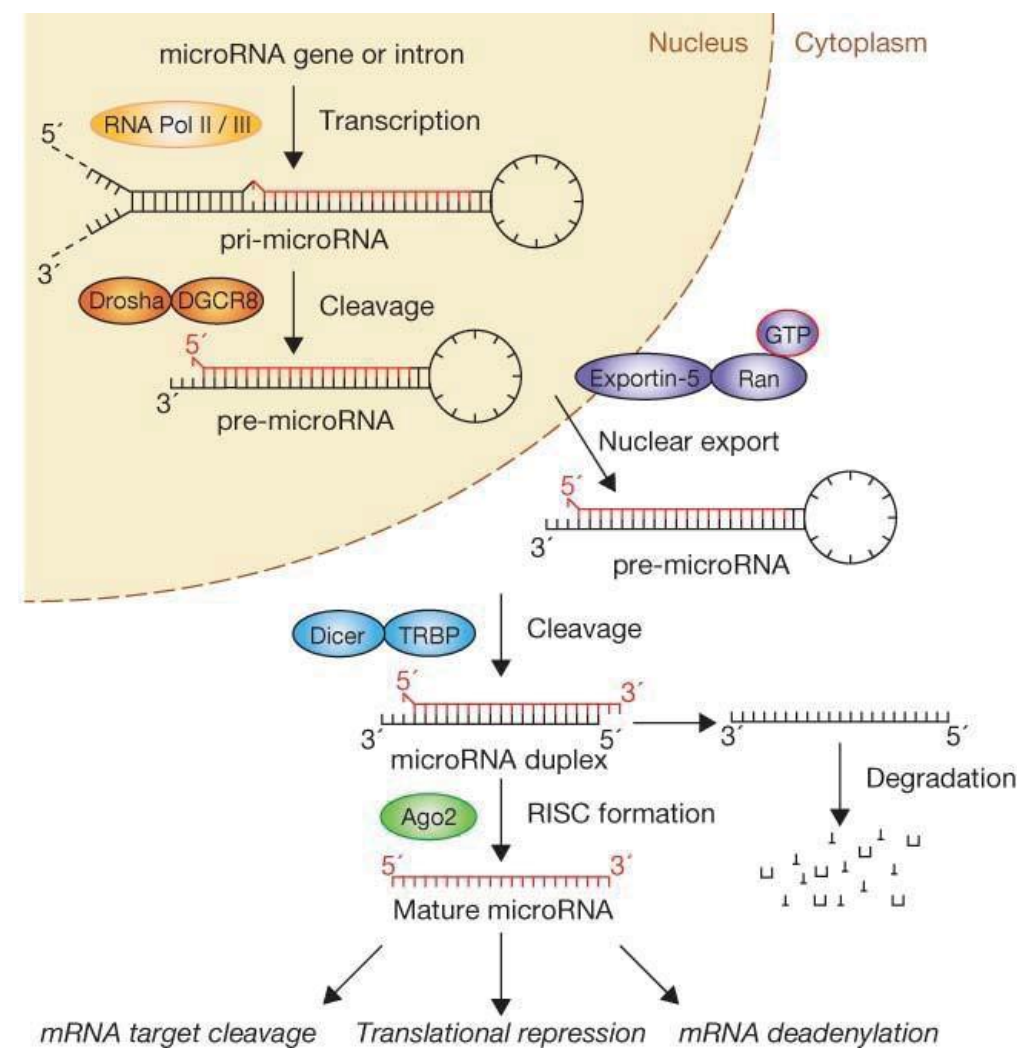

Figure 1.3 Diagram of miRNA biogenesis in animals. miRNAs are first transcribed into pri-miRNA and undergone the processing of Drosha. After exportation out of nucleus, Dicer, TAR RNA-binding protein (TARBP2), protein activator of the interferon induced protein kinase (PACT) and Argonaute (AGO2) 
(22) mediate the cleavage of pre-miRNA and are assembled to RNA-induced silencing complex (RISC). Adapted from (24).

MicroRNAs play diverse roles in many biological processes, including proliferation, differentiation and apoptosis. Dysregulations of miRNAs thus are involved in various diseases like cancer and diabetes. Several miRNAs have been identified as pathological factors contribute to the development of diabetes(25).Previously, miR-375 was found to be elevated in patients with type 2 diabetes. Overexpression of miR-375 results in reduced expression of mytrophin (MTPN) and t-SNAREs yeast homologue $1 \mathrm{~A}$ (Vtila), leading to impairment of insulin secretion(26,27).MiR-375 was further found to be required for maintain 1-cell mass. Genetic deletion of miR-375 impairs the proliferation of pancreas and results in a severely diabetic state, whereas the miR-375 knockout mice have increased pancreatic alpha cell mass and glucagon levels(28). miR$30 \mathrm{~d}$ was shown to associate with the expression of MafA, an insulin gene transcription factors as well as prevent the reduction of IRS-2 from tumor necrosis factor alpha(TNF-a) exposure(29).MiR-29a/b/c was increased in isolated islets of prediabetic non-obese diabetic (30) mice with impaired insulin secretion(31). Other miRNAs regulating pancreatic 1-cell function include miR144 that was upregulated in blood, pancreas, liver and skeletal muscles of type 2 diabetes model rats $(32,33)$ and miR-24 that overpression inhibited insulin secretion and 1-cell proliferation by targeting two maturity onset diabetes of youth (MODY) genes (34).

\subsection{Let-7 family of microRNAs}

In this study, we identified the specific functions of a highly conserved miRNA family, let-7, in pancreatic 1-cells. Let-7family of miRNAs is one of the most abundant miRNAs expressed among animals. In mice, there are nine differentlet7 members encoded by 12 genes in which let-7a has identical sequence across various species from $C$. elegans to human. All of let- 7 family members are believed to have similar functions because of the same seed sequences in their mature form $(35,36)$. Let-7 family was first identified as tumor suppressor by negatively regulating many oncogenes. In human cancers, loss of let-7 was 
discovered resulting in upregulation of some cell-cycle factors, including RAS, MYC, HMGA2 (high mobility group AT-hook 2), cyclin D and CDC34. Increasing of these let-7-targeted genes leads to dysfunction of cell growth and proliferation and termination of normal differentiation and the emergence of malignancy(3739). Interestingly, let-7a was nevertheless found to suppress cytokine-induced cancer cell death by inhibiting the expression of caspase-3, an executioner caspase that initiate apoptosis (19) (Figure 1.2). Let-7 family also regulated glucose metabolism in multiple organ through lin28/let-7 axis. Lin28 and let-7 were mutually antagonistic regulators involved in glucose homeostasis. Lin28 transgenic mice were resistant to obesity and diabetes and exhibited enhanced glucose tolerance. Hao Zhu and his colleagues reported that proteins associated with insulin signaling, such as IRS-2, IGF1R (insulin-like growth factor 1receptor), PIK3IP1 (phosphoinositide-3-kinase interacting protein 1), Akt2 and EIF4EBP2 (eukaryotic translation initiation factor 4E-binding protein 2) were all predicted to contain let-7 binding sites(30). Further study indicated transgenic mice globally overexpress let-7 exhibited glucose intolerance and reduced glucose-stimulated insulin secretion. Glucose tolerance tests (GTT) and insulin tolerance tests (ITT) in transgenic mice suggested insulin resistance in peripheral tissues and the reduction of glucose tolerance was caused solely by insufficient insulin. Knock down of let-7 was sufficient to lead to increased insulin secretion and recovery of insulin sensitivity(36). Although being comprehensive and insightful, previous studies do not provide the information onlet-7in specific tissues and the function of let-7 in pancreatic 1-cells is incomplete and remains to be determined.

\subsection{Methods to silence/block miRNA family function}

miRNAs generally exist as multiple family members and display significant functional redundancy. Therefore, it is important to silence specific miRNA and reveal its biological function and its underlying regulatory networks. Currently, there are three approaches used for loss of miRNA function: genetic knockouts, miRNA sponges and antisense oligonucleotides(40). The traditional methods for gene functions by gene knockout are not very effective in studies of miRNA because of the small sizes and multiplicity of miRNA genes distributed over the 
intergenic regions(41). miRNA sponges are transgenes that express in cells and generate the transcripts containing multiple miRNA binding sites. The promoterdriven sponges are allowed to contain a fluorescence reporter gene for identification and selection(42). Another approach in miRNA loss-of-function studies is to introduce chemically synthesized antisense oligucleotides, or antimiRs. The antimiRs are presumed to anneal to and block the mature miRNA through sequence complementarities(43).

In this study, we construct the short tandem target mimic (STTM) to block the functions of miRNA. STTM is a powerful technology complementary to miRNA sponges. STTM is an artificial non-coding RNA consists of two miRNA binding sites and a spacer linker(Figure 1.4). The binding sites for a miRNA are perfectly complementary to their targets with a bulge at the central three nucleotides in order to prevent miRNA mediated cleavage and degradation. The spacer is 4888 nucleotides long with a weak hairpin secondary structure $(41,44)$.

Effectiveness of STTM has been confirmed by STTM-165/166 in plant (45) and STTM-30 in pancreatic 1-cells (44).

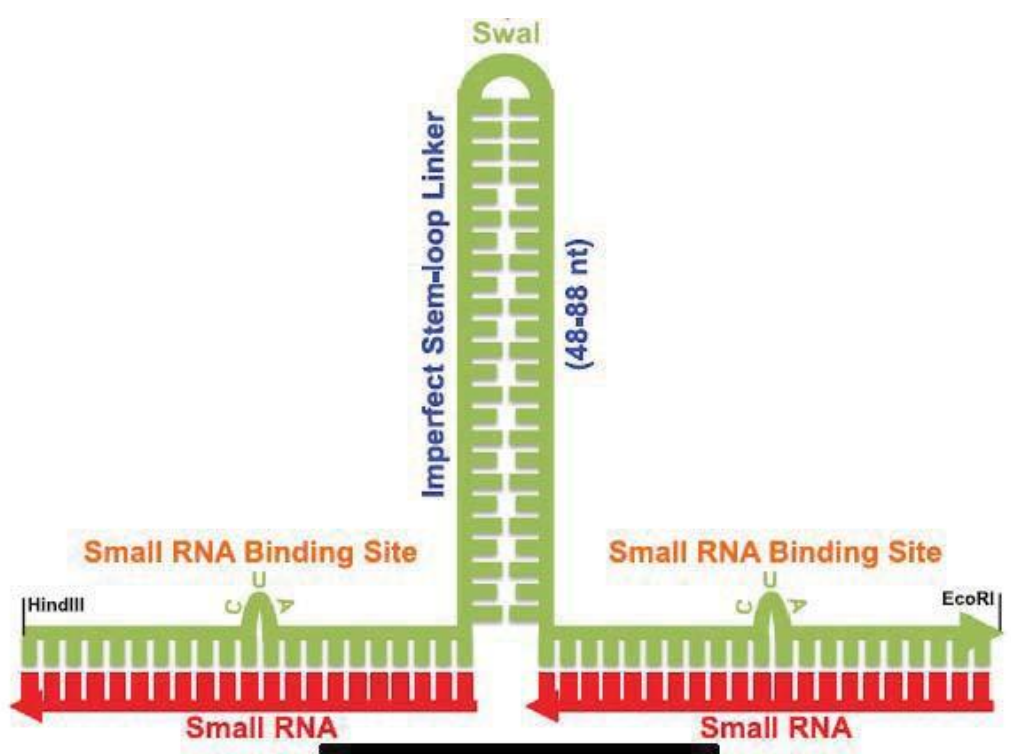

STTM-Small RNA Complex

Figure 1.4 Structure of STTM RNA transcripts. A 48-88 nt spacer with the stem loop structure is flanked by two small RNA binding sites. The bulge 
introduced into binding sites stabilizes the interactions with miRNA and prevents itself from being cleaved. Adapted from (44). 


\section{Objective}

In this study, the objective was to identify the biological functions of let-7

microRNA in pancreatic 1-cells by blocking expression of endogenous let-7 using STTM methods. The hypothesis is that changes of let-7 in pancreatic 1-cells can result in significant differences in cell proliferation, cell death as well as insulin secretion of 1-cells. The mainly objective of this work is to examine the target gene regulated by let- 7 and investigate the molecular mechanisms underlying the biological alterations. 


\section{Materials and methods}

\section{Construction of STTM-let7}

To block the expression of both let-7a and let-7b in pancreatic 1-cells, a STTM sequence complementary to let-7a (AACTATACAACCctaTACTACCTCA) and let-7b (AACCACACAACCctaTACTACCTC) with an $88 \mathrm{nt}$ spacer in between (total $138 \mathrm{bp}$ ) was synthesized and cloned into the pEGP-miR vector as described (44) (Figure 3.1).

A

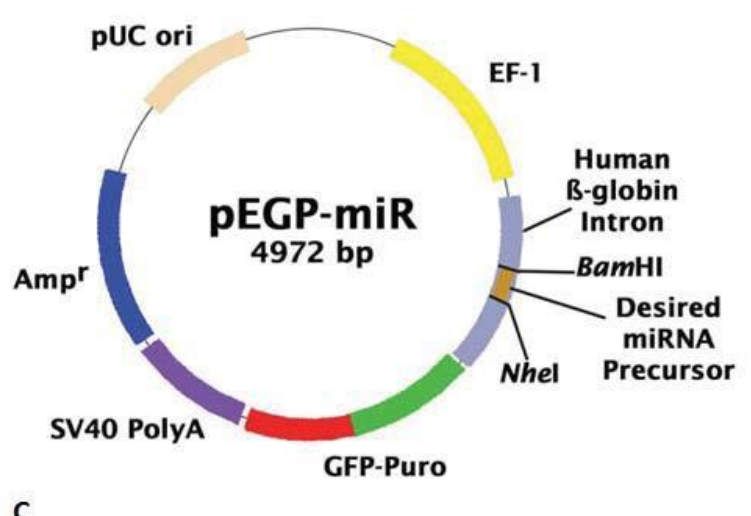

B

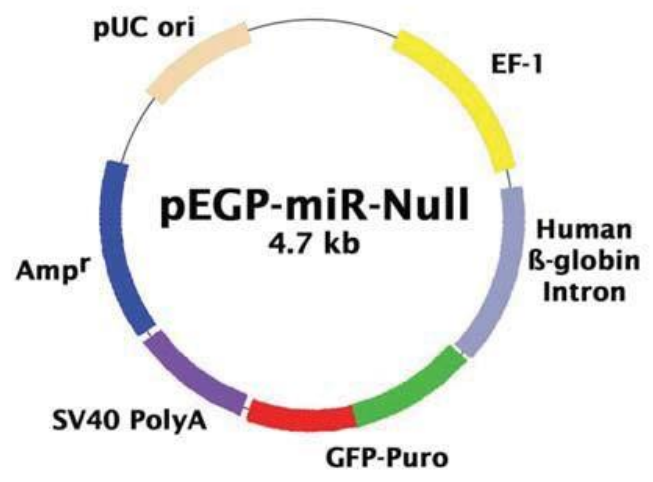

STTMlet7a/b(138bp)

GgatccAACTATACAACCCTATACTACCTCAGTTGTTGTTGTTATGGTCTAGTTGTTGTTGTTATGGTCTAATTTAAATATGGT CTAAAGAAGAAGAATATGGTCTAAAGAAGAAGAATAACCACACAACCCTATACTACCTCAGctagc

Ggatcc: BamHl; Gctagc: Nhel

Figure 3.1 Schematic representations of pEGP-miR cloning and expression vector for STTM-let7a/b and pEGP-miR Null control vector. (A) pEGP-miR (4972bp). The two sites for cloning of STTM in Human 1-globin intron are BamHI and Nhel. Positions indicating EF-1a promoter, GFP-Puro fusion protein, SV40 Polyadenylation signal and the human 1-globin intron are shown in the diagram. (B) pEGP-miR Null (4.7kb). The pEGP-miR Null control vector cannot be digested with BamHI due to secondary structure. (C) The sequences of STTMlet7a/b cloned into $\mathrm{pEGP-miR}$ vector. Two restriction enzyme recognition sites (BamHI and Nhel) are shown.

\section{Cell culture and transfection}


The pancreatic 1-cell line MIN6 was cultured in DMEM/high glucose (Thermo Scientific, Waltham, MA) with $15 \%$ fetal bovine serum (FBS) (Atlanta biologicals, Flowery Branch, GA), 100U/ml penicillin and $100 \mathrm{U} / \mathrm{ml}$ streptomycin. Cells were maintained in a $5 \% \mathrm{CO}_{2}$ humidified atmosphere incubator (Thermo Scientific, Waltham, MA) at $37 \mathrm{C}$. The culture medium was replaced every $48 \mathrm{~h}$. For transfection, MIN6 cells were trypsinized and pelleted at $700 \mathrm{rpm}$ for $3 \mathrm{~min}$. Cell pellets were resuspended in $100 \mu \mathrm{l}$ Nucleofector buffer (4D Nucleofector X kit L) (Lonza, Basel, Switzerland). $10 \mu \mathrm{g}$ of plasmids for pEGP-STTM-let7 and pEGPNull control vector were used for transfection according to the protocol. 3 days after transfection, MIN6 cells were treated with cytokines mix $(10 \mathrm{ng} / \mathrm{ml}, \mathrm{IL}-11$, IFN-y and TNF-a) for 12-24h.

\section{Isolation of pancreatic islets and virus infection}

Islets were isolated from 10- to 16-week wild type mouse using collagenase digestion and cultured in RPMI medium. After incubating for $24 \mathrm{~h}$, islets were infected with recombinant adenovirus as previously described (46)and plated in $60 \mathrm{~mm}$ Petri-dish. Islets were collected 2 days after infection and perform western blot as described below.

\section{Luciferase reporter assay}

To evaluate the silencing efficiency of STTM-let7, let-7a complementary sequence or mutant was subcloned into the pRLTK vector (Promega, Madison, $\mathrm{WI})$. For the luciferase reporter assay, pRLTK reporter constructs $(2 \mu \mathrm{g})$ were electorporated into MIN6 cells $\left(10^{6}\right)$ with pEGP-STTM-let7 or pEGP-Null control vector using Amaxa (Lonza). The plasmid PGL-3 containing firefly luciferase $(2 \mu \mathrm{g})$ was co-transfected together to normalize for transfection efficiency. Luciferase activity was measured with a dual-luciferase reporter assay kit (Promega) two days after transfection.

\section{RNA isolation and real-time PCR}

Total RNA from MIN6 or islets was extracted using Trizol reagent (Roche, Basel, Switzerland) or miRNasy Mini Kit (QIAGEN, Venlo, Netherlands) and reversetranscribed using TaqMan MicroRNA Reverse Transcription Kit (Applied 
Biosystems, Carlsbad, CA). Quantitative RT-PCR was performed using the SYBR Green Master Mix and StepOnePlus Real-Time PCR System (Applied Biosystem). miRNA levels were normalized by the relative expression of U6.

\section{Western blot analysis}

MIN6 cells were cultured and treated as described above and lysed with lysis buffer containing $50 \mathrm{mM}$ HEPES, $150 \mathrm{mM} \mathrm{NaCl}, 1 \mathrm{mM}$ EDTA, 1\% Triton, 0.2\% SDS, phosphatase inhibitor and proteinase inhibitor (1 ml, Sigma, St. Louis, MO). Protein concentration was determined using PierceBCA Protein Assay Kit (Thermo Scientific) and $150 \mu$ gtotal protein samples were separated by SDSPAGE. Immunoblotting was performed with antibodies purchased from Cell Signaling (Beverly, MA) diluted according to the protocols.

\section{Cell proliferation assay}

DNA synthesis was measured using cell proliferation ELISA kit (Roche). MIN6 cells were transfected as described. At $48 \mathrm{~h}$ after transfection, cells were collected and seeded in a 96-well plate to the density of $4 \times 10^{4}$ per well. BrdU were added to culture medium to a final concentration of $10 \mu \mathrm{M}$. After BrdU labeling for $12-24 \mathrm{~h}$, the cells were processed according to the protocol.

\section{Cell Apoptosis}

At $48 \mathrm{~h}$ after transfection, cells were collected and seeded in a 96-well plate. After incubating in the plate for $24 \mathrm{~h}$, cytokines mix was added to culture medium to the final concentration of $10 \mathrm{ng} / \mathrm{ml}$. According to the cell death detection ELISA (Roche) kit, anti-histone biotin and anti-DNA-POD were added to each well to measure the levels of cell death.

\section{Glucose Stimulated Insulin secretion}

As described above, MIN6 cells were seeded in $35 \mathrm{~mm}$ dish and incubated for 3 days followed by 12-24h treatment of cytokines mix. Afterwards, cells were preincubated for $2 \mathrm{~h}$ in Krebs-Ringer bicarbonate HEPES buffer (KRB) and then cultured in KRB containing $25 \mathrm{mM}$ glucose for $1 \mathrm{~h}$. After the incubation period, supernatants were collected for stimulated insulin secretion and cell pellets were 
processed for total insulin content. Insulin levels were measured using Mouse Insulin ELISA Kit (Mercodia, Uppsala, Sweden) and normalized to DNA concentration of the cell pellets.

\section{Statistical analysis}

For comparisons, statistical significance was evaluated using a two-tailed Student $t$ test. A $p$ value of less than 0.05 was considered significant. 


\section{Results}

\subsection{STTM-let7 reduces expression of let-7 in 1-cells}

The STTM-let7a/b constructed was synthesized and ligated with pEGP-miR vector that digested using $\mathrm{BamHI}$ and Nhel as described above. To investigate the expression of STTM-let7 and inhibition of endogenous let-7, pEPG-Null control vector and pEGP-STTM-let7 were transfected into MIN6 cells respectively. Cells were collected for Northern blot to detect the expression level of let-7a. Endogenous let-7a was down-regulated in cells transfected withSTTM-let7 compared with control group(Figure 4.1 A).In order to further determine the silencing efficiency of STTM-let7, let-7a or mutant let-7 recognition sites were cloned into 3'UTR of pRLTK luciferase vector and luciferase reporter assays were performed. Co-transfection with STTM-let7was capable of decreasing luciferase activity of the wild type constructs, whereas the reporter with mutant let-7 sites was not affected (Figure 4.1 B).

A

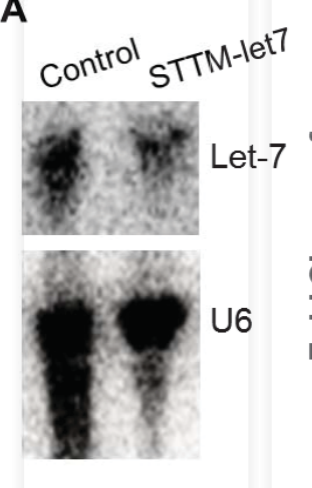

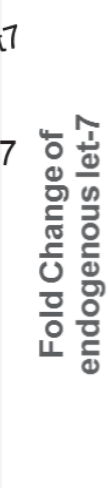

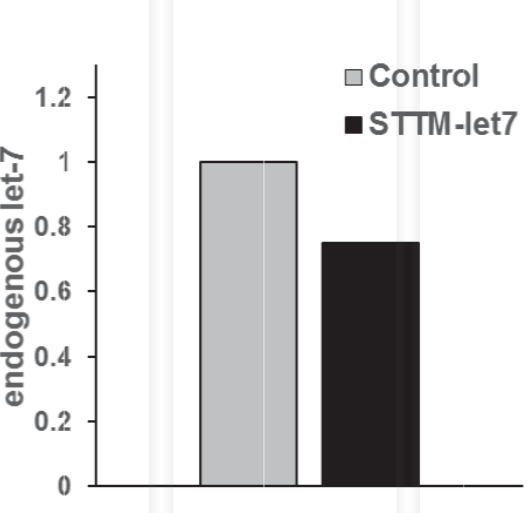

B

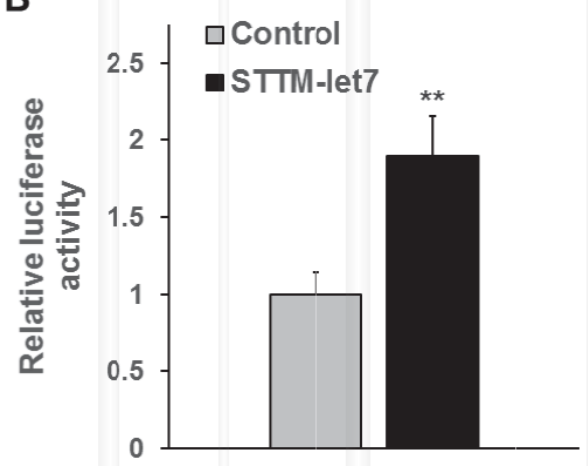

Figure 4.1 STTM-let7 reduces the expression of let-7. A: Northern blot analysis of total RNA from MIN6 cells transfected with pEGP-STTM-let7 or pEGP-Null control vectors with ${ }^{32} \mathrm{P}$-labeled let-7a probe (left). Let-7 level was normalized to $\mathrm{U} 6$ as fold change(right). B: the pRLTK-let7 luciferase reporter construct was co-transfected into MIN6 cells along with pEGP-STTM-let7 or pEGP-Null control, respectively. The luciferase activities were normalized by the co-transfected pGL3 firefly luciferase activity. ${ }^{* *}, P<0.01$

\subsection{Let-7 suppress cell death by targeting caspase-3}


To understand the biological effects caused by the decrease of let-7 in 1-cells, we examined the expression level of let-7 targets by western blot. As expected, expression of caspase-3, which was reported to be one oflet-7 targets(19), was elevated when endogenous let-7 was inhibited by STTM (Figure 4.2 A, B) in MIN6 cells and islets. Caspase-3 belongs to the group of effector caspase family, which are located downstream of cell death pathway and can be activated through intrinsic pathway (Mitochondria) or extrinsic pathway (ligand-receptor binding)(17). Activation of Caspase-3 requires proteolytic cleavage of itself into $17 \mathrm{kDa}$ and $12 \mathrm{kDa}$ subunits. The intrinsic apoptotic pathway is mainly mediated by $\mathrm{Bcl}-2$ family members that center at mitochondria. Bax and $\mathrm{Bcl}-2$, two antagonistic Bcl-2 family proteins regulating apoptosis, were all increased by STTM-let7independent of cytokines induced extrinsic cell death pathway. The elevation of $\mathrm{Bcl}-2$ family by inhibition of let- 7 suggested let- 7 might play critical roles on regulating cell death.

The effect of let-7 on cell death was confirmed through cell death assay in MIN6 cells. In the presence of cytokines treatment, inhibition of let-7 by introducing STTM-let7 significantly increased cell death, which was correlated to the increased Caspase-3 expression (Figure 4.2 C). Under normal growth conditions, MIN6 cells displayed a low level of cell death rate and inhibition of let-7 had no effect. 
A

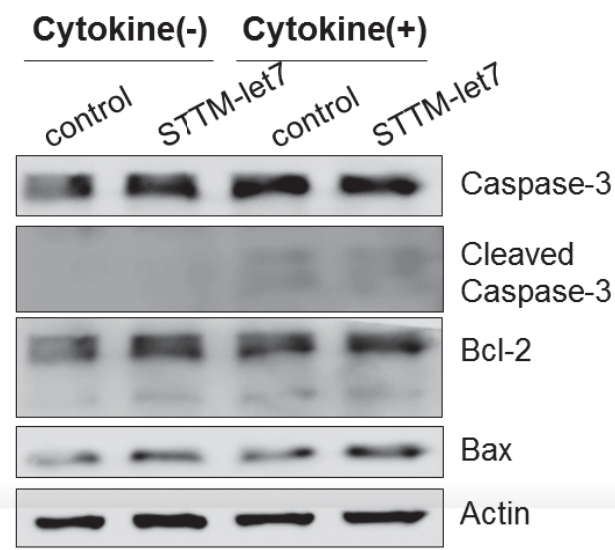

C

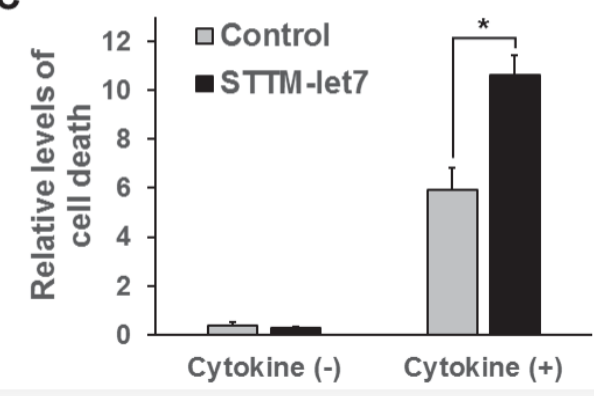

B

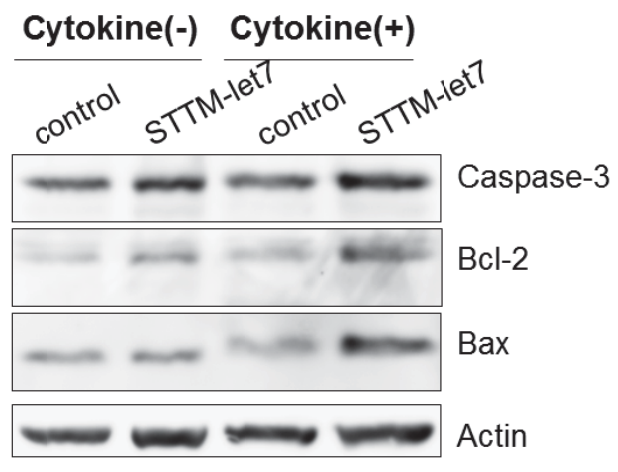

Figure 4.2 Inhibition of let-7 by STTM-let7 induces cell death by targeting caspase-3. A: STTM-let7 increased the expression of caspase-3 and Bax. MIN6 cells were transfected with STTM-let7 or control vector, After $48 \mathrm{~h}$, cells were treated with cytokine $(10 \mu \mathrm{g} / \mathrm{ml})$ for $16 \mathrm{~h}$ and the expression of caspase-3, cleaved caspase-3, Bcl-2 and Bax were measured by Western blot. B: STTM-let7 increased the expression of caspase-3 and Bax in isolated islets infected with AD-STTM-let7 virus. C: STTM-let-7 Increased cytokine-induced cell death in MIN6 cells. ${ }^{*}, \mathrm{P}<0.05$.

\subsection{Let-7 promotes 1-cell proliferation}

To assess the contribution of let-7 to cell proliferation, BrdU incorporation was performed in MIN6 cells after transfection. After incubating for 24h, STTM-let7 was capable of decreasing BrdU signal and inhibiting cell proliferation (Figure 4.3 A).For the cells treated with cytokines, there was no difference in BrdU signal because of the intensive cell death rate. Western blot analysis indicated that IRS- 
2 and mTOR, two factors involved in insulin signaling and regulate 1-cell function, were both down-regulated by STTM-let7 (Figure 4.3 B). However, the expression of Akt and phosphor-Akt was not changed significantly. Akt2 was predicted containing the miRNA recognition sites of let- 7 and it was phosphorylated by mTOR complex 2 (mTORC2) at Serine 473 (47). Activation of Akt2 subsequently phosphorylates mTOR at Serine 2448 and results in activation of mTOR complex 1 (mTORC1). On the other hand, one of the insulin transcription factors, MafA, was not affected by STTM-let7 as expected for the reason of lacking let-7 recognition sites. However, STTM-let7 had no significant effects on the expression of mTOR, IRS-2 and Akt in islets with AD-STTM-let7 (data not shown).

A

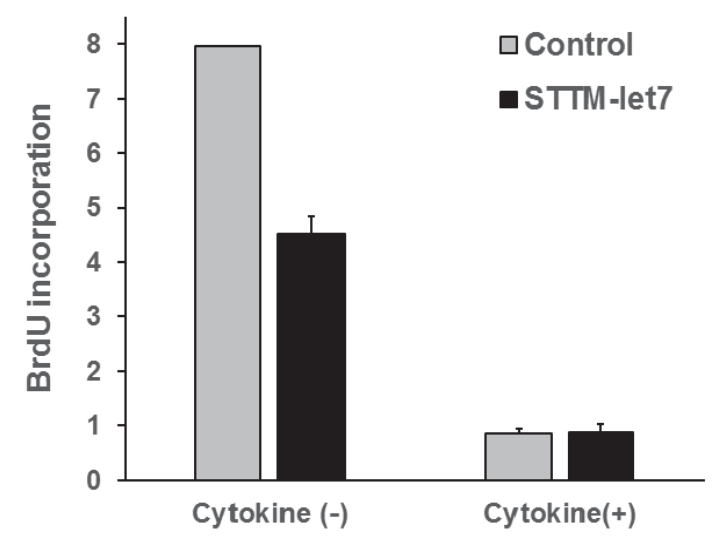

B

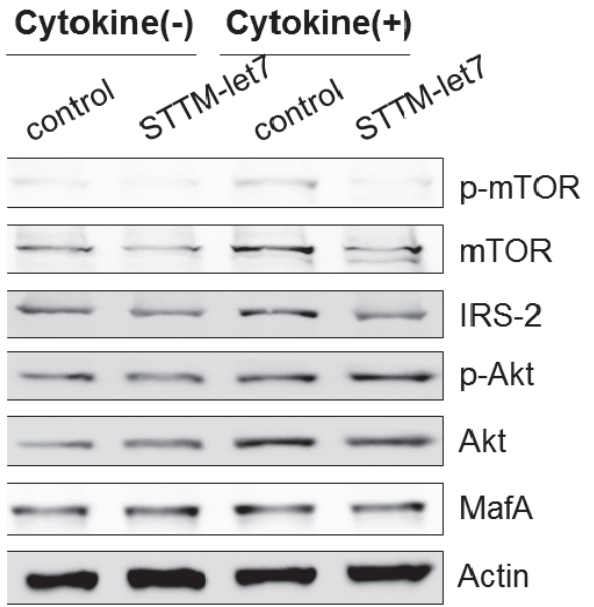

Figure 4.3 Inhibition of let-7 by STTM-let7 inhibit 1-cell proliferation by down-regulating insulin signaling. A: MIN6 cells were transfected with STTMlet7 or control vector. After $48 \mathrm{~h}$, cell proliferation was measure by BrdU incorporation after incubated with cytokine $(10 \mu \mathrm{g} / \mathrm{ml})$ for $16 \mathrm{~h}$. B: Western blot validated that STTM-let7 decreased the expression of IRS-2, p-Akt, p-mTOR and mTOR. The expression of MafA had no significant effect.

\subsection{Let-7 positively regulates glucose-stimulated insulin secretion}

Glucose stimulated insulin secretion assay of MIN6 cells was performed to investigate the effects of let-7 on 1-cell function. Increased glucose level is 
capable of inducing insulin secretion by causing production of ATP and elevation of cellular $\mathrm{Ca}^{2+}$, and finally leads to the release of synthesized insulin from secretory vesicles. Consistent with the repressed insulin signaling,STTMlet7inhibited glucose-stimulated insulin secretion as well as total insulin content(Figure 4.4 A, B). Given the previous studies about insulin exocytosis was associated with insulin signaling (15), IRS-1 and PI3 kinase act as regulators controlling intracellular $\mathrm{Ca}^{2+}$ released from endoplasmic reticulum. As a result, the inhibition of insulin signaling in 1-cells also contributes to the reduction of insulin secretion.
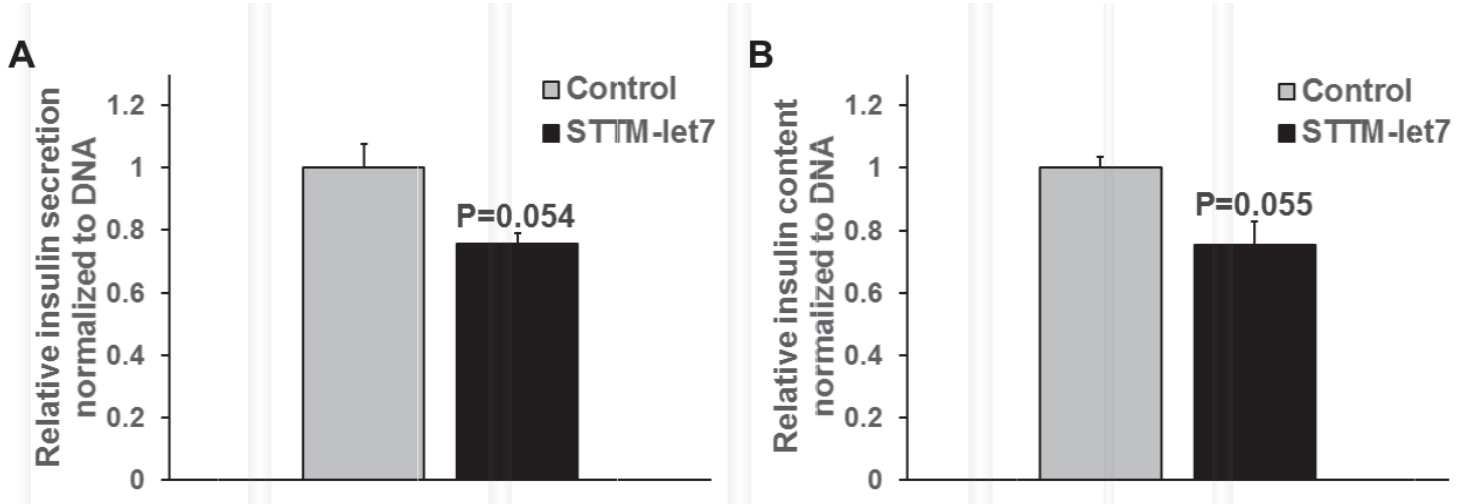

Figure 4.4 Inhibition of let-7 by STTM-let7 decreased insulin secretion in pancreatic beta cells.MIN6 cells were transfected with STTM-let7 or control vector. After $48 \mathrm{~h}$, the secreted insulin in the medium (A) and insulin content (B) were quantified using mouse insulin ELISA and normalized to total DNA. The presented data are the average of three independent experiments \pm S.D. 


\section{Discussion}

In this study, we observed that the expression of let-7 family was successfully blocked by the newly developed STTM technology. Inhibition of let-7 by STTMlet7 reduced 1-cell proliferation and induced 1-cell death through Caspase-3 mediated apoptosis pathway. Moreover, reduced let-7 expression impaired insulin signaling and decreased glucose-stimulated insulin secretion. Taken together, let-7 promotes 1-cell proliferation and protects against cytokine-induced apoptosis. Let-7 also plays a key role in regulating insulin secretion by activating insulin signaling.

Although let-7 was revealed to regulate apoptotic cell death by negatively regulating Caspase-3, whether other factors involved in cell death signaling are affected is less known. In this study, we show that let-7 inhibits two factors controlling initiation of cell death, Bax and Bcl-2. The elevation of Bax and Bcl-2 can be observed in MIN6 cells transfected with STTM-let7 with or without cytokines treatments, indicating let-7 regulates cells death independent of cytokine-induced extrinsic pathway. Cell death ELISA assay indicates that upregulation of Caspase-3 by STTM-let7 sufficiently lead to a significant increase in cell death after cytokines inducement. Caspase-3 exists as an inactive form that is triggered by extracellular or intracellular stimulations through activation of initiator caspases (Caspase 8, 9 and 10) (17). Although increased Bax/Bcl-2 ratio was observed associated with increased Caspase-3 and apoptosis (48), the other caspases (caspase-8 or -9 ) downstream from Bax/Bcl-2 were not affected in the studies where caspase-3 was inhibited by overexpression of let-7(19). It could be the reason that $\mathrm{Bax}$ and $\mathrm{Bcl}-2$ are up-regulated at the same extent and $\mathrm{Bax} / \mathrm{Bcl}-2$ ratio remains the same without affecting the downstream cell signaling. Whether let-7 inhibits the expression of Bax and Bcl-2 directly is unknown, however, let-7plays a role in regulating the center of cell death, Caspase-3.

Based on previous reports that let-7 can regulate glucose metabolism through Lin28/let-7 axis (30), let-7 controls glucose homeostasis and affects insulin sensitivity in muscles and liver by suppressing insulin signaling pathways. Insulin receptor (INSR), IRS-2, insulin-like growth factor 1 receptor (IGF1R), mTOR and Akt2 were confirmed to be regulated by let-7 through luciferase reporter assay $(30,36)$. However, the previous studies primarily focused on insulin action on 
insulin-target tissues rather than insulin secretion. Here, let-7 was revealed to promote insulin secretion and insulin signaling in 1-cells. IRS-2, which capable of promoting 1-cell growth and function (13), could play critical roles in let-7 mediated activation of insulin signaling. Decreased insulin secretion observed in cells transfected with STTM-let7 can be caused by inactivation of insulin signaling or impaired cell proliferation. Frost and Olson (36) have reported the decreased insulin secretion in let-7 globally knock-out mice. Theoretically, absent of let-7 in pancreas should promote insulin signaling and result in enhanced 1cell function. However, a low level of insulin secretion in transgenic mice was observed, suggesting the potential effects of let-7 on maintaining glucose homeostasis. In our study, the inhibition of IRS-2 and mTOR in the presence of STTM-let7 indicates the reversal of let-7 effects on the mRNA of these genes. In contrast, the other let-7 target, Akt2 was not changed. The other isoform of Akt, Akt1 was ever revealed to regulate cell cycle by regulating Cyclin D1 and cyclindependent kinase-4 (49). Both of Akt1 and Akt2 were activated through mTORC2-mediated phosphorylation at Serine 473(47) although only Akt2 was predicted to be regulated by let-7. Absence of the alteration in Akt and p-Akt could be caused by the slight change of Akt expression and the antibody targeting total Akt content. The unaffected phosphor-Akt also suggests phosphorylation of Akt was not influenced by the decreased mTOR in mTOR Complex 2. Although an intact mTOR Complex requires phosphorylation of mTOR, recent data renders that $\mathrm{mTOR}$ is phosphorylated diversely when associated with mTORC1 and mTORC2 (50). The specific phosphorylation of mTOR in mTORC1 is primarily on Serine 2448 whereas mTOR in mTORC2 is phosphorylated on Serine 2481. It is mTORC2 that phosphorylate Akt1 and Akt2 at Serine 473. mTORC1 locates downstream from Akt and is activated through insulin signaling. Phospho-mTOR at Serine 2448 was detected and revealed to be repressed because of STTM-let7 (Figure 4.3 B). Unaltered phosphor-Akt provides the evidence that decrease of phosphor-mTOR only results from the low expression of mTOR, regardless of the activation of phosphor-Akt. Indeed, Ser2448 phosphorylation of mTOR was reported to be regulated by p70S6 kinase downstream from mTOR (51).

Other studies demonstrate that the effect of let-7a on target mRNA is reversed in immune-stimulated cells (52) and translation of HMGA2 is activated by let-7 in 
the cells arrested in Gophase of cell cycle (53).Bhattacharyya, et al discovered that he reversal of miRNA repression was mediated by mRNA processing bodies ( $P$ bodies) in response to different stress conditions (54). However, it is not confirmed whether the activation of insulin signaling by let-7 results from stressinduced reversal of mRNA repression. And in islets consist of alpha cells and 1cells, IRS-2 and mTOR wasn't changed significantly by STTM-let7, suggesting let-7 may play different roles in different types of cell.

The decrease of insulin secretion caused by down-regulation of let-7 in MIN6 cells can be a combination of inhibited 1-cell growth and deactivation of insulin signaling. Changes of total insulin content suggest the let-7 promotes insulin expression by regulating cell proliferation. And essentially, insulin signaling also influences the $\mathrm{Ca}^{2+}$ level and directly affect the exocytosis of insulin vesicles (15). As mentioned above, increase of $\mathrm{Ca}+$ was revealed partially dependent on IRS-1 and PI3 kinase(55). Recent data also indicates various intracellular factors involved in cell signaling contribute greatly to GSIS in compared with glucose itself (56). From the previously studies regarding the effects of insulin molecules on insulin secretion (15), it can be inferred there is a complex feedback mechanism that helps 1-cells auto-regulate their functions through insulin signaling. 


\section{Future work}

In this study, the effects of let-7 on pancreatic 1-cells were mainly focused on MIN6 cell line. And the molecular mechanisms underlying the biological changes were not fully understood. In future work, STTM-let7 can be used for repression of let-7 in mice islets. Insulin promoter region will be used driving the expression of STTM in the 1-cell of mouse pancreas. Whether let-7 regulates 1-cell function can be determined in vivo by examining glucose metabolism in the transgenic mice. Globally inhibition of let-7 in mouse had been shown associated with increased insulin sensitivity and enhanced glucose tolerance (36). For the mouse specifically inhibit let-7 in 1-cells, glucose tolerance tests (GTT) will be performed to confirm the response of 1 -cell to glucose stimulation.

The action of let-7 in other tissue cells should be examined for comparison with let-7 in 1-cells. Insulin signaling pathways in different tissues may be responsible for various functions and thus they are mediated in different manners. Another strategy resolving the question is to silence one of the genes involved in insulin signaling. Let-7 mediated 1-cell function could base on either a combination of multiple let-7 target genes or a few critical genes. In addition, the activation time of insulin signaling presumably leads to diverse effects on insulin secretion in response to glucose (15).

Although well known as a tumor suppressor, let-7 was recently reported to regulate cell death by targeting Fas (57) and Caspase-3 (19). Our work further revealed let-7-mediated apoptosis was associated with $\mathrm{Bax} / \mathrm{Bcl}-2$ ratio in mitochondria. It is essential to examine the miRNA involved cell death signaling in other types of cell. Overexpression of let- 7 in those cells will provide more information about let-7 effects on cell growth and cell death.

Finally, 1-cell mass can be measured in isolated islets from the transgenic mice specifically silence let-7 in pancreas. Considering the low proliferation rate and apoptosis rate of 1-cells, whether absence of let-7 will result in a significant difference is unknown. Since let-7 is responsible for regulating glucose homeostasis and insulin sensitivity, dysfunction of let-7 in 1-cells may also contribute to the development of type 2 diabetes.

\section{Conclusion}


Short tandem target mimic (STTM) is capable of inhibiting the expression of endogenous microRNA let-7 in pancreatic 1-cells. Let-7 miRNA family plays significant roles on the normal function of 1-cells. Through STTM approach, let-7 was shown to protect 1-cells from cytokine induced cell death by suppressing Bax-Caspase-3 apoptotic cascade. Moreover, for the first time let-7 was revealed to regulate insulin signaling by controlling the expression of several factors responsible for 1-cell proliferation and insulin secretion.IRS-2 and mTOR were both found to be promoted by let-7. The study of let-7 in pancreatic 1-cells suggests the function of insulin signaling pathways in insulin-producing cells and provides potential targets that may contribute to therapeutic treatments of type 2 diabetes. 


\section{References}

1. Sampanis, C. (2008) Management of hyperglycemia in patients with diabetes mellitus and chronic renal failure. Hippokratia 12, 22-27

2. Burn, P. (2010) Type 1 diabetes. Nature reviews. Drug discovery 9, 187188

3. Grundy, S. M., Benjamin, I. J., Burke, G. L., Chait, A., Eckel, R. H., Howard, B. V., Mitch, W., Smith, S. C., and Sowers, J. R. (1999) Diabetes and Cardiovascular Disease: A Statement for Healthcare Professionals From the American Heart Association. Circulation 100, 1134-1146

4. Smyth, S., and Heron, A. (2006) Diabetes and obesity: the twin epidemics. Nat Med 12, 75-80

5. Riserus, U., Willett, W. C., and Hu, F. B. (2009) Dietary fats and prevention of type 2 diabetes. Progress in Lipid Research 48, 44-51

6. Shanik, M. H., Xu, Y., Skrha, J., Dankner, R., Zick, Y., and Roth, J. (2008) Insulin Resistance and Hyperinsulinemia: Is hyperinsulinemia the cart or the horse? Diabetes Care 31, S262-S268

7. Robertson, R. P. (2004) Chronic Oxidative Stress as a Central Mechanism for Glucose Toxicity in Pancreatic Islet Beta Cells in Diabetes. Journal of Biological Chemistry 279, 42351-42354

8. Harmon, J. S., Gleason, C. E., Tanaka, Y., Oseid, E. A., Hunter-Berger, K. K., and Robertson, R. P. (1999) In vivo prevention of hyperglycemia also prevents glucotoxic effects on PDX-1 and insulin gene expression. Diabetes 48, 1995-2000

9. Federici, M., Hribal, M., Perego, L., Ranalli, M., Caradonna, Z., Perego, C., Usellini, L., Nano, R., Bonini, P., Bertuzzi, F., Marlier, L. N. J. L., Davalli, A. M., Carandente, O., Pontiroli, A. E., Melino, G., Marchetti, P., Lauro, R., Sesti, G., and Folli, F. (2001) High Glucose Causes Apoptosis in Cultured Human Pancreatic Islets of Langerhans: A Potential Role for Regulation of Specific Bcl Family Genes Toward an Apoptotic Cell Death Program.

Diabetes 50, 1290-1301

10. Assmann, A., Ueki, K., Winnay, J. N., Kadowaki, T., and Kulkarni, R. N. (2009) Glucose Effects on Beta-Cell Growth and Survival Require Activation of Insulin Receptors and Insulin Receptor Substrate 2. Molecular and Cellular Biology 29, 3219-3228 
11. Xu, G. G., and Rothenberg, P. L. (1998) Insulin Receptor Signaling in the 1-Cell Influences Insulin Gene Expression and Insulin Content: Evidence for Autocrine 1-Cell Regulation. Diabetes 47, 1243-1252

12. Leibiger, B., Leibiger, I. B., Moede, T., Kemper, S., Kulkarni, R. N., Kahn, C. R., de Vargas, L. M., and Berggren, P.-O. (2001) Selective Insulin Signaling through A and B Insulin Receptors Regulates Transcription of Insulin and Glucokinase Genes in Pancreatic 1 Cells. Molecular Cell 7, 559-570

13. Park, S., Dong, X., Fisher, T. L., Dunn, S., Omer, A. K., Weir, G., and White, M. F. (2006) Exendin-4 Uses Irs2 Signaling to Mediate Pancreatic 1 Cell Growth and Function. Journal of Biological Chemistry 281, 11591168

14. Briaud, I., Dickson, L. M., Lingohr, M. K., McCuaig, J. F., Lawrence, J. C., and Rhodes, C. J. (2005) Insulin Receptor Substrate-2 Proteasomal Degradation Mediated by a Mammalian Target of Rapamycin (mTOR)induced Negative Feedback Down-regulates Protein Kinase B-mediated Signaling Pathway in 1-Cells. Journal of Biological Chemistry 280, 22822293

15. Leibiger, I. B., Leibiger, B., and Berggren, P.-O. (2008) Insulin Signaling in the Pancreatic 1-Cell. Annual Review of Nutrition 28, 233-251

16. Grunnet, L. G., Aikin, R., Tonnesen, M. F., Paraskevas, S., Blaabjerg, L., StOrling, J., Rosenberg, L., Billestrup, N., Maysinger, D., and MandrupPoulsen, T. (2009) Proinflammatory Cytokines Activate the Intrinsic Apoptotic Pathway in 1-Cells. Diabetes 58, 1807-1815

17. Jin, Z., and El-Deiry, W. S. (2005) Overview of cell death signaling pathways. Cancer Biology \& Therapy 4, 147-171

18. Kim, H.-E., Du, F., Fang, M., and Wang, X. (2005) Formation of apoptosome is initiated by cytochrome c-induced dATP hydrolysis and subsequent nucleotide exchange on Apaf-1. Proceedings of the National Academy of Sciences of the United States of America 102, 17545-17550

19. Tsang, W., and Kwok, T. (2008) Let-7a microRNA suppresses therapeutics-induced cancer cell death by targeting caspase-3. Apoptosis 13, 1215-1222

20. Bartel, D. P. (2009) MicroRNAs: Target Recognition and Regulatory Functions. Cell 136, 215-233 
21. Bentwich, I., Avniel, A., Karov, Y., Aharonov, R., Gilad, S., Barad, O., Barzilai, A., Einat, P., Einav, U., Meiri, E., Sharon, E., Spector, Y., and Bentwich, Z. (2005) Identification of hundreds of conserved and nonconserved human microRNAs. Nat Genet 37, 766-770

22. Herrera, B. M., Lockstone, H. E., Taylor, J. M., Wills, Q. F., Kaisaki, P. J., Barrett, A., Camps, C., Fernandez, C., Ragoussis, J., Gauguier, D., McCarthy, M. I., and Lindgren, C. M. (2009) MicroRNA-125a is overexpressed in insulin target tissues in a spontaneous rat model of Type 2 Diabetes. BMC medical genomics 2, 54

23. Bartel, D. P. (2004) MicroRNAs: Genomics, Biogenesis, Mechanism, and Function. Cell 116, 281-297

24. Winter, J., Jung, S., Keller, S., Gregory, R. I., and Diederichs, S. (2009) Many roads to maturity: microRNA biogenesis pathways and their regulation. Nat Cell Biol 11, 228-234

25. Kantharidis, P., Wang, B., Carew, R. M., and Lan, H. Y. (2011) Diabetes Complications: The MicroRNA Perspective. Diabetes 60, 1832-1837

26. Poy, M. N., Eliasson, L., Krutzfeldt, J., Kuwajima, S., Ma, X., MacDonald, P. E., Pfeffer, S., Tuschl, T., Rajewsky, N., Rorsman, P., and Stoffel, M. (2004) A pancreatic islet-specific microRNA regulates insulin secretion. Nature 432, 226-230

27. Zhao, H., Guan, J., Lee, H. M., Sui, Y., He, L., Siu, J. J., Tse, P. P., Tong, P. C., Lai, F. M., and Chan, J. C. (2010) Up-regulated pancreatic tissue microRNA-375 associates with human type 2 diabetes through beta-cell deficit and islet amyloid deposition. Pancreas 39, 843-846

28. Poy, M. N., Hausser, J., Trajkovski, M., Braun, M., Collins, S., Rorsman, P., Zavolan, M., and Stoffel, M. (2009) miR-375 maintains normal pancreatic a- and 1-cell mass. Proceedings of the National Academy of Sciences 106, 5813-5818

29. Zhao, X., Mohan, R., Ozcan, S., and Tang, X. (2012) MicroRNA-30d induces insulin transcription factor MafA and insulin production by targeting mitogen-activated protein 4 kinase 4 (MAP4K4) in pancreatic beta-cells. The Journal of biological chemistry 287, 31155-31164

30. Zhu, H., Shyh-Chang, N., Segre, A. V., Shinoda, G., Shah, S. P., Einhorn, W. S., Takeuchi, A., Engreitz, J. M., Hagan, J. P., Kharas, M. G., Urbach, A., Thornton, J. E., Triboulet, R., Gregory, R. I., Consortium, D., 
Investigators, M., Altshuler, D., and Daley, G. Q. (2011) The Lin28/let-7 axis regulates glucose metabolism. Cell 147, 81-94

31. Roggli, E., Gattesco, S., Caille, D., Briet, C., Boitard, C., Meda, P., and Regazzi, R. (2012) Changes in MicroRNA Expression Contribute to Pancreatic 1-Cell Dysfunction in Prediabetic NOD Mice. Diabetes 61, 1742-1751

32. Mao, Y., Mohan, R., Zhang, S., and Tang, X. (2013) MicroRNAs as pharmacological targets in diabetes. Pharmacological Research 75, 37-47

33. Karolina, D. S., Armugam, A., Tavintharan, S., Wong, M. T. K., Lim, S. C., Sum, C. F., and Jeyaseelan, K. (2011) MicroRNA 144 Impairs Insulin Signaling by Inhibiting the Expression of Insulin Receptor Substrate 1 in Type 2 Diabetes Mellitus. PLOS ONE 6, e22839

34. Zhu, Y., You, W., Wang, H., Li, Y., Qiao, N., Shi, Y., Zhang, C., Bleich, D., and Han, X. (2013) MicroRNA-24/MODY Gene Regulatory Pathway Mediates Pancreatic 1-Cell Dysfunction. Diabetes 62, 3194-3206

35. Roush, S., and Slack, F. J. (2008) The let-7 family of microRNAs. Trends in cell biology 18, 505-516

36. Frost, R. J. A., and Olson, E. N. (2011) Control of glucose homeostasis and insulin sensitivity by the Let-7 family of microRNAs. Proceedings of the National Academy of Sciences

37. Lee, Y. S., and Dutta, A. (2007) The tumor suppressor microRNA let-7 represses the HMGA2 oncogene. Genes \& development 21, 1025-1030

38. Johnson, S. M., Grosshans, H., Shingara, J., Byrom, M., Jarvis, R., Cheng, A., Labourier, E., Reinert, K. L., Brown, D., and Slack, F. J. (2005) RAS Is Regulated by the let-7 MicroRNA Family. Cell 120, 635-647

39. Johnson, C. D., Esquela-Kerscher, A., Stefani, G., Byrom, M., Kelnar, K., Ovcharenko, D., Wilson, M., Wang, X., Shelton, J., Shingara, J., Chin, L., Brown, D., and Slack, F. J. (2007) The let-7 MicroRNA Represses Cell Proliferation Pathways in Human Cells. Cancer Research 67, 7713-7722

40. Stenvang, J., Petri, A., Lindow, M., Obad, S., and Kauppinen, S. (2012) Inhibition of microRNA function by antimiR oligonucleotides. Silence 3, 1

41. Tang, G., and Tang, X. (2013) Short Tandem Target Mimic: A Long Journey to the Engineered Molecular Landmine for Selective Destruction/Blockage of MicroRNAs in Plants and Animals. Journal of Genetics and Genomics 40, 291-296 
42. Ebert, M. S., Neilson, J. R., and Sharp, P. A. (2007) MicroRNA sponges: competitive inhibitors of small RNAs in mammalian cells. Nat Meth 4, 721726

43. Davis, S., Lollo, B., Freier, S., and Esau, C. (2006) Improved targeting of miRNA with antisense oligonucleotides. Nucleic Acids Research 34, 22942304

44. Tang, G., Yan, J., Gu, Y., Qiao, M., Fan, R., Mao, Y., and Tang, X. (2012) Construction of short tandem target mimic (STTM) to block the functions of plant and animal microRNAs. Methods 58, 118-125

45. Yan, J., Gu, Y., Jia, X., Kang, W., Pan, S., Tang, X., Chen, X., and Tang, G. (2012) Effective small RNA destruction by the expression of a short tandem target mimic in Arabidopsis. The Plant cell 24, 415-427

46. Takahashi, R., Ishihara, H., Takahashi, K., Tamura, A., Yamaguchi, S., Yamada, T., Katagiri, H., and Oka, Y. (2007) Efficient and controlled gene expression in mouse pancreatic islets by arterial delivery of tetracyclineinducible adenoviral vectors. Journal of Molecular Endocrinology 38, 127136

47. Betz, C., Stracka, D., Prescianotto-Baschong, C., Frieden, M., Demaurex, N., and Hall, M. N. (2013) mTOR complex 2-Akt signaling at mitochondriaassociated endoplasmic reticulum membranes (MAM) regulates mitochondrial physiology. Proceedings of the National Academy of Sciences 110, 12526-12534

48. SALAKOU, S., KARDAMAKIS, D., TSAMANDAS, A. C., ZOLOTA, V., APOSTOLAKIS, E., TZELEPI, V., PAPATHANASOPOULOS, P., BONIKOS, D. S., PAPAPETROPOULOS, T., PETSAS, T., and DOUGENIS, D. (2007) Increased Bax/Bcl-2 Ratio Up-regulates Caspase3 and Increases Apoptosis in the Thymus of Patients with Myasthenia Gravis. In Vivo 21, 123-132

49. Fatrai, S., Elghazi, L., Balcazar, N., Cras-Meneur, C., Krits, I., Kiyokawa, H., and Bernal-Mizrachi, E. (2006) Akt Induces 1-Cell Proliferation by Regulating Cyclin D1, Cyclin D2, and p21 Levels and Cyclin-Dependent Kinase-4 Activity. Diabetes 55, 318-325

50. Copp, J., Manning, G., and Hunter, T. (2009) TORC-Specific Phosphorylation of Mammalian Target of Rapamycin (mTOR): Phospho- 
Ser2481 Is a Marker for Intact mTOR Signaling Complex 2. Cancer Research 69, 1821-1827

51. Chiang, G. G., and Abraham, R. T. (2005) Phosphorylation of Mammalian Target of Rapamycin (mTOR) at Ser-2448 Is Mediated by p70S6 Kinase. Journal of Biological Chemistry 280, 25485-25490

52. Chafin, C. B., Regna, N. L., Caudell, D. L., and Reilly, C. M. (2014) MicroRNA-let-7a promotes E2F-mediated cell proliferation and NF[kgr]B activation in vitro. Cell Mol Immunol 11, 79-83

53. Vasudevan, S., Tong, Y., and Steitz, J. A. (2008) Cell cycle control of microRNA-mediated translation regulation. Cell Cycle 7, 1545-1549

54. BHATTACHARYYA, S. N., HABERMACHER, R., MARTINE, U., CLOSS, E. I., and FILIPOWICZ, W. (2006) Stress-induced Reversal of MicroRNA Repression and mRNA P-body Localization in Human Cells. Cold Spring Harbor Symposia on Quantitative Biology 71, 513-521

55. Aspinwall, C. A., Qian, W.-J., Roper, M. G., Kulkarni, R. N., Kahn, C. R., and Kennedy, R. T. (2000) Roles of Insulin Receptor Substrate-1, Phosphatidylinositol 3-Kinase, and Release of Intracellular Ca2+ Stores in Insulin-stimulated Insulin Secretion in 1-Cells. Journal of Biological Chemistry 275, 22331-22338

56. Komatsu, M., Takei, M., Ishii, H., and Sato, Y. (2013) Glucose-stimulated insulin secretion: A newer perspective. Journal of Diabetes Investigation 4, 511-516

57. Wang, S., Tang, Y., Cui, H., Zhao, X., Luo, X., Pan, W., Huang, X., and Shen, N. (2011) Let-7/miR-98 regulate Fas and Fas-mediated apoptosis. Genes Immun 12, 149-154 